\title{
不同环境条件下磷酸盐玻璃滤光片腐蚀特性研究
}

\author{
王乔方 ${ }^{1,2}$, 王冲文 ${ }^{2}$, 郑万祥 ${ }^{1}$, 刘 剑 ${ }^{2}$, 罗 瑞 ${ }^{1,2}$, 赵远荣 ${ }^{2}$
}

(1. 昆明物理研究所, 云南 昆明 650223; 2. 国营第二九八厂, 云南 昆明 650114)

\begin{abstract}
摘要: 采用投样试验方法, 对磷酸盐玻璃滤光片在万宁热带海洋环境及西双版纳热带雨林环境分别 进行自然环境暴露试验, 对在两种环境条件下试验的滤光片进行表面形貌观察、腐蚀失重量变化统 计及腐蚀速率研究, 分析不同环境条件下滤光片的腐蚀特性。试验结果表明, 滤光片在热带雨林和 热带海洋环境暴露腐蚀规律基本一致, 但滤光片在热带海洋环境下的腐蚀速率大于热带雨林环境下 的, 且相同试验环境下未镀膜的滤光片比镀保护膜 $\mathrm{MgF}_{2}$ 的滤光片腐蚀速率更大。
\end{abstract}

关键词: 滤光片; 热带海洋; 热带雨林; 失重量; 腐蚀速率

中图分类号：TG171 文献标识码：A 文章编号：1001-8891(2020)10-0947-06

\section{Corrosion Properties of Phosphate Glass Filter under Different Environments}

\author{
WANG Qiaofang ${ }^{1,2}$, WANG Chongwen ${ }^{2}$, ZHENG Wanxiang ${ }^{1}$, LIU Jian ${ }^{2}$, LUO Rui ${ }^{1,2}$, ZHAO Yuanrong ${ }^{2}$
}

(1. Kunming Institute of Physics, Kunming 650223, China; 2. State-Owned No. 298 Factory, Kunming 650114, China)

\begin{abstract}
By applying a sample test method, phosphate glass filters were tested in the tropical ocean environment of Wanning and the tropical rainforest environment of Xishuangbanna. Through observations and statistical analyses of the corrosion rate, weight-loss variation, and surface morphology under the two experimental environments, the corrosion characteristics of the filter under different environmental conditions were studied. The test results showed that the corrosion law was the same for the filters in the tropical rainforest and tropical ocean. However, the corrosion rate of the filter in the tropical ocean was greater than that in the tropical rainforest. The corrosion rate of the filter without a film was higher than that of the filter coated with $\mathrm{MgF}_{2}$. This study has introduced a method for improving the anti-corrosion ability of filters.
\end{abstract}

Key words: phosphate glass, filter, tropical ocean, tropical rainforest, weight loss, corrosion rate

\section{0 引言}

随着南海周边安全局势的演变, 我国武器装备的 使用环境逐渐由传统的内陆环境向沿海、岛礁、深海 等环境拓展。高温高湿、高盐雾的复杂环境容易导致 武器装备材料及结构的腐蚀和破坏 ${ }^{[1]}$, 由此引发武器 装备在高温高湿及高盐雾环境的适应性问题日益突 出。磷酸盐玻璃 $\mathrm{LB}_{6}$ 滤光片的透射光谱范围为 492 $577 \mathrm{~nm}$, 是观瞄武器装备中常用的光学零件 ${ }^{[2]}$, 滤光 片的环境适应能力直接影响光电观瞄设备的可靠性, 经统计分析发现, 引起光电设备显示系统故障或失效 的元器件中, 滤光片腐蚀失效约占 $39 \%$ 。这对滤光片 的可靠性提出了更高的要求。因而, 研究滤光片在高 温高湿、高盐雾环境中的环境适应性是产品可靠性控
制的重要环节。目前国内外对滤光片的自然环境适应 性, 特别是对其在高温高湿、高盐雾环境中的环境适 应性研究报道较少。

磷酸盐玻璃的主要成分为 $\mathrm{P}_{2} \mathrm{O}_{5}$, 由 $(\mathrm{PO} 4)^{3-}$ 四面体 相互连成网络, 具有透紫外线、低色散等特点 ${ }^{[3]}$, 磷 酸盐玻璃作为特种玻璃在各个领域都有广泛的应用, 如用来制造光学玻璃、透紫外线玻璃、吸热玻璃、耐 氟酸玻璃等, 但其缺点主要表现为化学稳定性差 ${ }^{[3-9]}$ 。 本文以抛光滤光片及镀保护膜滤光片为研究对象, 选 择具有高温高湿、高盐雾气候特征的万宁和具有高温 高湿气候特征的西双版纳试验站进行自然暴露试验, 通过腐蚀特性及腐蚀失重量的对比分析, 开展磷酸盐 玻璃滤光片在热带雨林和热带海洋两种不同环境条件 下的腐蚀特性研究。 


\section{1 实验方法}

\section{1 试验样品}

试验样品分别为经表面抛光后未镀膜及镀保护膜 $\mathrm{MgF}_{2}$ 的两种滤光片, 表面光洁度 $B=\mathrm{IV}$ 。试验前进行 原始质量称量记录, 试样表面用 $80 \%$ 的乙醇和 $20 \%$ 的 乙醚混合液清擦干净, 烘干后, 在干燥容器中静置 $48 \mathrm{~h}$ 恒重后称量试样质量, 精确至 $1 \mathrm{mg}$ 。分别在西双版纳、 万宁进行户外暴露试验, 每半年为 1 个试验周期, 共 进行 2 年试验。每隔半年对滤光片进行外观检查、测 试光学性能及腐蚀产物分析研究。采用式(1)计算暴露 试样的腐蚀速率 $D$ :

$$
D=\Delta W / S t \rho
$$

式中: $\Delta W$ 为腐蚀质量损失; $S$ 为暴露表面积; $t$ 为试 验时间; $\rho$ 为试样密度。

\section{2 检测}

试样回收后, 采用 DSC-V1 数码相机观察记录滤 光片表面的宏观腐蚀形貌。采用 Primotech 显微镜观 察滤光片表面的微观腐蚀形貌。采用 $\mathrm{X}$ 射线光电子能 谱仪（X-ray photoelectron spectroscopy, XPS）对腐蚀 产物进行测试分析。利用光谱仪分析不同试验周期滤 光片的光谱特性变化规律。将试样用新配置的 $5 \%$ 的 盐酸溶液浸泡 $2 \mathrm{~min}$, 在常温下利用超声波清洗 $2 \mathrm{~min}$, 除去表面腐蚀产物, 再经过烘干、静置恒重 $24 \mathrm{~h}$ 后, 使用 ME204 电子天平称量滤光片的腐蚀失重量。

\section{3 自然试验环境}

自然环境试验在海南万宁及云南西双版纳试验站 开展, 其中, 万宁试验站为典型的热带海洋气候, 西 双版纳试验站为典型的热带雨林气候 ${ }^{[10]}$ 。西双版纳试 验站和万宁试验站的年气象因素数据如表 1 所示、介 质因素数据如表 2 所示, 万宁站的温湿度略高于西双 版纳站, 其雨水 $\mathrm{pH}$ 值小于西双版纳站, 酸性更强。

\section{2 实验结果}

\section{1 腐蚀形貌}

\subsection{1 宏观腐蚀形貌}

未镀保护膜滤光片及镀保护膜 $\mathrm{MgF}_{2}$ 滤光片在热 带海洋及热带雨林环境下的腐蚀现象均主要表现为表 面出现灰白色腐蚀产物。未镀保护膜滤光片在万宁和 西双版纳直接暴露 6 个月后, 表面出现局部腐蚀现象, 腐蚀产物呈灰白色。随着暴露时间的延长, 腐蚀面积 逐渐增加。暴露 24 个月后, 试样表面严重腐蚀, 表面 完全被乳白色粉末状物质覆盖, 如图 1 所示。

镀 $\mathrm{MgF}_{2}$ 保护膜滤光片在万宁和西双版纳直接暴 露 6 个月, 膜层出现局部点状腐蚀, 试样表面膜层开 裂, 如图 2 所示。暴露 18 个月后, 膜层出现龟裂状脱 落, 基底材料腐蚀, 局部表面被乳白色粉末状物质覆 盖。

\subsection{2 微观腐蚀形貌}

未镀保护膜滤光片经过 18 个月自然环境试验后 的扫描电镜（scan electron microscope, SEM）微观腐 蚀形貌如图 3 所示。

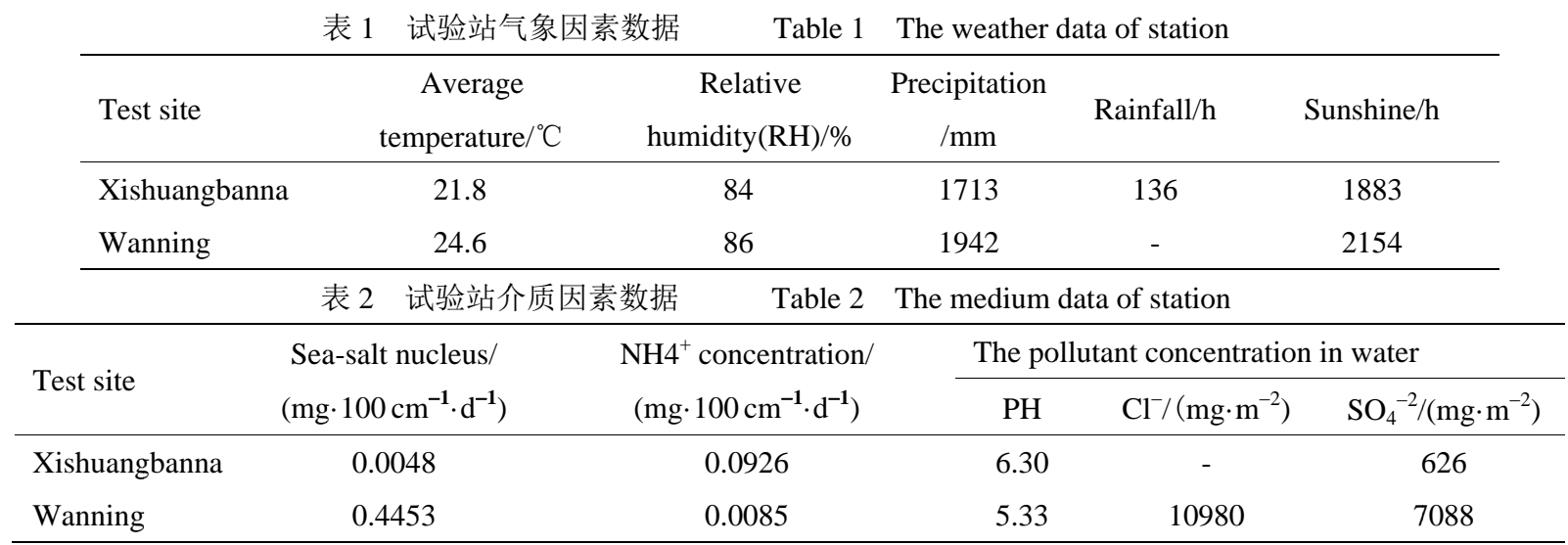

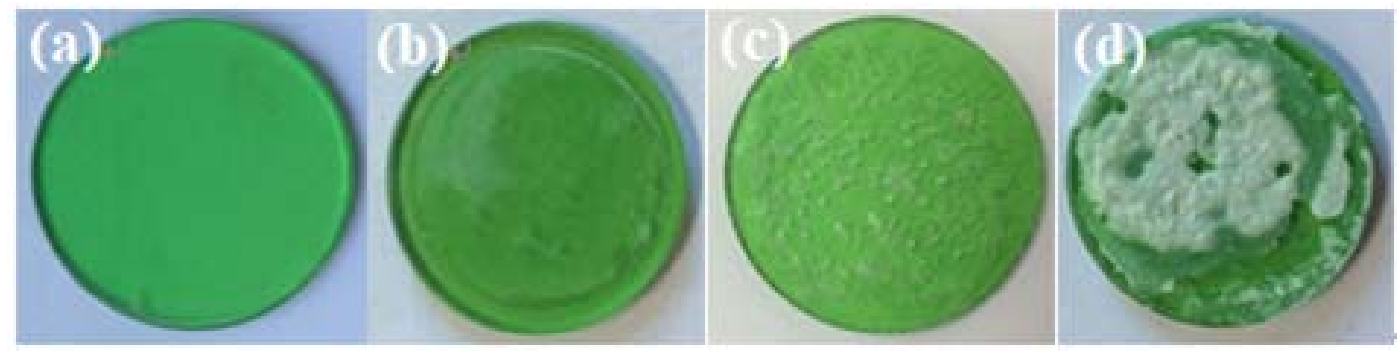

万宁站：(a)第一周期； (b)第二周期； (c)第三周期； (d) 第四周期

Wanning: (a) The first cycle; (b) The second cycle; (c)The third cycle(d) The fourth cycle 


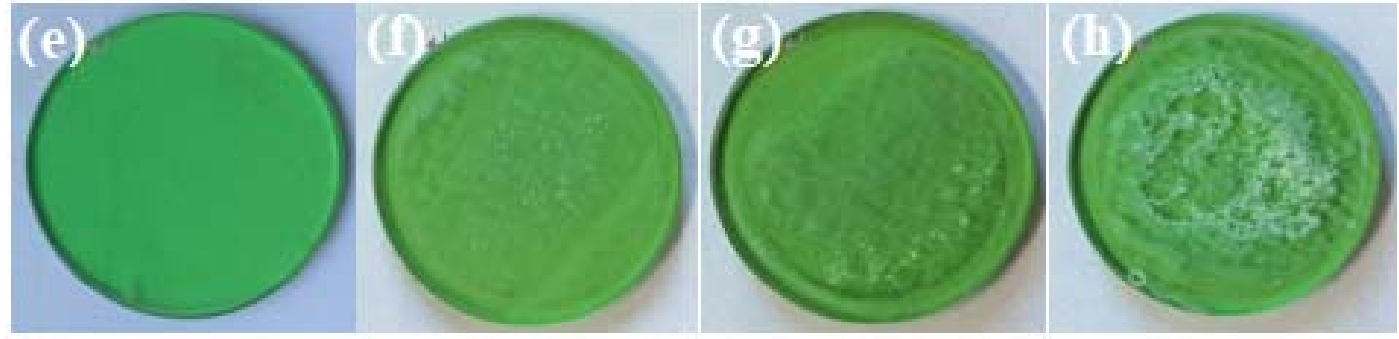

西双版纳站：(e) 第一周期；(f) 第二周期; (g) 第三周期; (h) 第四周期

Xishuangbanna: (e) The first cycle; (f) The second cycle; (g)The third cycle (h) The fourth cycle

图 1 未镀膜滤光片试验结果 Fig.1 The test results of filters without film in Xishuangbanna and Wanning

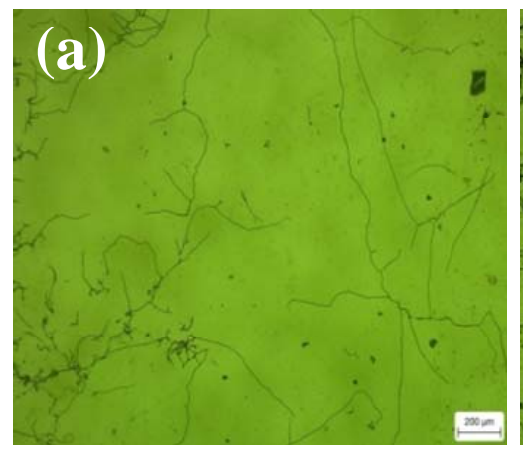

(a) 西双版纳站 (a) Xishuangbanna

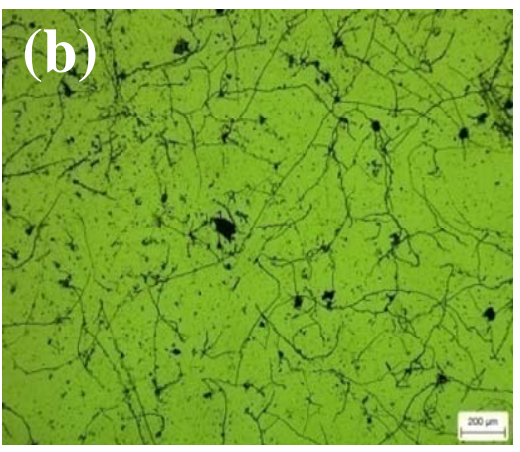

(b) 万宁站 (b) Wanning

图 2 镀保护膜滤光片在西双版纳站和万宁站暴露 6 个月显微图

Fig.2 The microscopic of filters with film after exposed six months in Xishuangbanna and Wanning

从图 3 看出, 未镀膜滤光片表面有大量的针叶状 腐蚀产物, 腐蚀产物较为疏松, 长度和宽度分别为 $20 \mu \mathrm{m}$ 和 $5 \mu \mathrm{m}$, 形状比较规则且尺寸大小均匀, 并且 有大量的网状裂纹。

镀保护膜滤光片在万宁站直接暴露 6 个月, 膜层 出现局部点状腐蚀, 如图 4(a)所示, 直接暴露 18 个月 后, 试样表面膜层开裂, 表面被乳白色粉末状物质覆 盖, 如图 4(b)所示。在西双版纳站直接暴露 6 个月, 膜 层出现少量点状腐蚀, 如图 4(c) 所示, 直接暴露 18 个 月后, 膜层局部出现龟裂状脱落, 基底材料局部腐蚀, 如图 4(d)所示。

2.1.3 腐蚀产物分析

图 5 为未镀膜和镀保护滤光片试验后表面析出

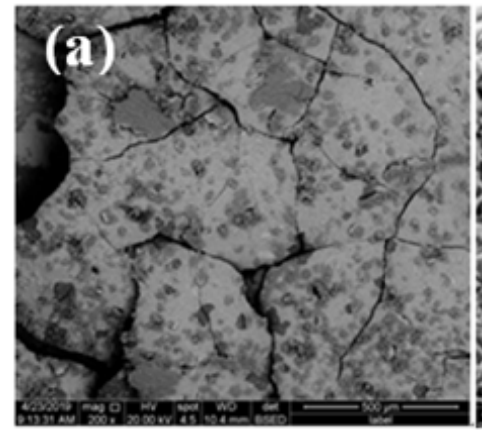

(a) 西双版纳站 (a) Xishuangbanna 物的 XPS 谱图, 分析可知, 表面出现 Mg、Zn、F、O、 $\mathrm{N} 、 \mathrm{C} 、 \mathrm{P} 、 \mathrm{Al}$ 等元素, 其中 $\mathrm{Mg} 1 \mathrm{~s}$ 结合能为 $1302.7 \mathrm{eV}$ 处的峰归属于 $\mathrm{Mg}(\mathrm{OH})_{2} ; \mathrm{Zn} 2 \mathrm{p}$ 结合能为 $1020.4 \mathrm{eV}$ 处 的峰归属于 $\mathrm{Zn}_{3} \mathrm{P}_{2}$, 结合能为 102.29 处对的峰归属于 $\mathrm{ZnP}_{2} ; \mathrm{F} 1 \mathrm{~s}$ 结合能为 $686.27 \mathrm{eV}$ 处的峰归属于 $\mathrm{AlF}_{3} \cdot 3 \mathrm{H}_{2} \mathrm{O}, \mathrm{F} 1 \mathrm{~s}$.ScanA 结合能为 $684.16 \mathrm{eV}$ 处的峰归 属于 KF; P2p 结合能为 $134.32 \mathrm{eV}$ 处的峰归属于 $\mathrm{NaPO}_{3}$, 结合能为 134.2 处的峰归属于 $\mathrm{PO}^{3-}$, P2p.ScanA 结合能为 $132.46 \mathrm{eV}$ 处的峰归属于 $\mathrm{Na}_{3} \mathrm{PO}_{4}$, 结合能为 132.36 处的峰归属于 $\left(\mathrm{PO}_{4}\right)^{3-}$; Al2p.ScanA 结合能为 73.82 处的峰归属于 $\mathrm{Al}_{2} \mathrm{O}_{3} ; \mathrm{K} 2 \mathrm{p} 3$ 结合能为 $293.05 \mathrm{eV}$ 处的峰归属于 $\mathrm{KF}$ 。其中氧含量最高, 主要

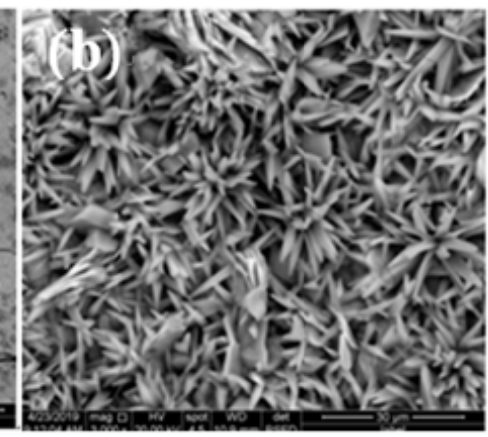

图 3 未镀膜滤光片暴露 18 个月的腐蚀显微图

Fig.3 The microscopic of filters without film after exposed eighteen months in Xishuangbanna and Wanning 
是由于磷酸盐滤光片基材和镀膜材料在长期自然环 境试验中发生氧化和水解反应。

\section{2 腐蚀速率}

滤光片在万宁站和西双版纳站暴露不同周期后 的腐蚀速率如图 6 所示, 可以看出, 试验相同周期时, 滤光片在万宁站的腐蚀速率均高于西双版纳站的, 这 主要是由于除相近的高温高湿环境因素外, 万宁站的 自然环境中腐蚀介质物浓度更高, 大气自然环境为弱 酸性, 可与水化后的弱碱性材料发生反应, 会加剧材 料表面的腐蚀速度 ${ }^{[2-3]}$ 。从图中还可以看出, 镀有保护 膜的滤光片腐蚀速率明显偏小, 第一周期时仅约为未 镀膜滤光片的 $1 / 5$, 说明所镀膜层对滤光片基材腐蚀 具有一定的保护作用, 但在经过第一个周期的自然环 境试验后, 由于保护层受到破坏, 第二、三、四周期 防护能力出现降低现象, 腐蚀速率约为未镀膜滤光片

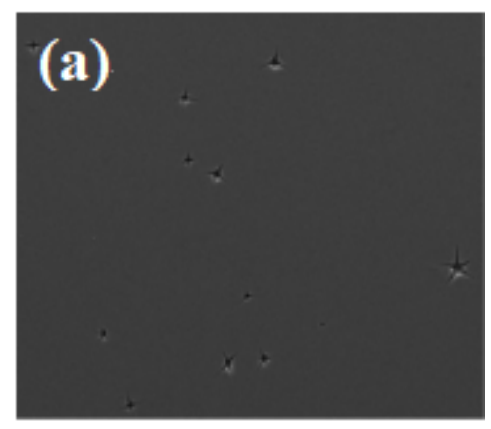

(a) 万宁站试验 6 个月(a) Six months' experiment in Wanning (b)

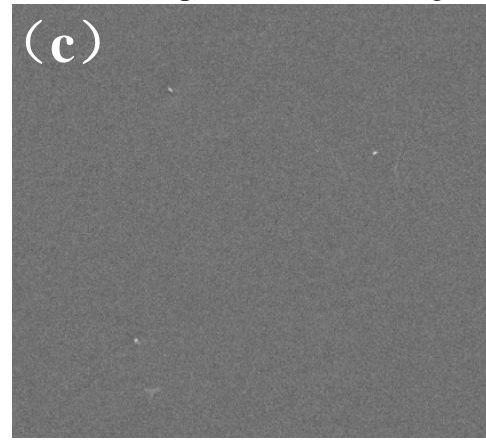

(c) 西双版纳站试验 6 个月

(c) Six months' experiment in Xishuangbanna

图 4 镀保护膜滤光片 SEM 图

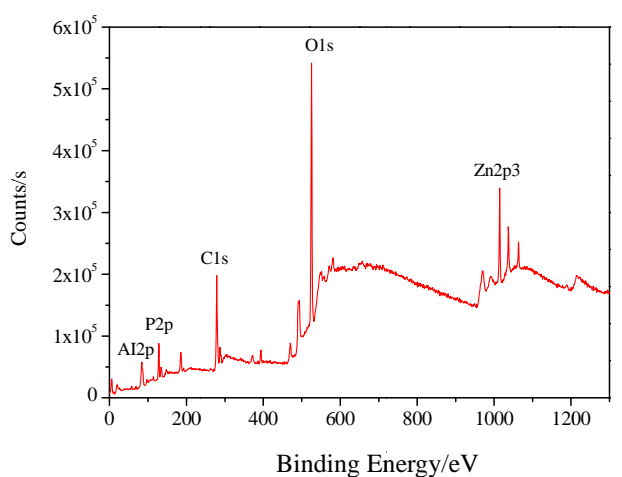

(a) 未镀膜滤光片 (a) The filter without film

图 5 滤光片析出物质 XPS 图
的 $1 / 2$ 。此外, 随着暴露时间的延长, 滤光片在各暴 露试验环境的腐蚀速率均减少, 说明腐蚀速率随时间 的延长而趋于稳定。

未镀保护膜滤光片经过热带雨林和热带海洋不 同环境试验, 腐蚀失重量百分比随时间的变化规律如 图 7 所示。

从图 7 可以看出, 滤光片在不同区域的腐蚀失重 量百分比与暴露时间遵循幂函数变化规律:

$$
F(t)=A t^{n}
$$

式中: $F(t)$ 为腐蚀失重量百分比; $t$ 为试验时间; $A$ 为 拟合常数; $n$ 为表征腐蚀发展趋势的常数, 其数值越 小说明耐腐蚀性能越好。对数据进行幂函数拟合分 析, 拟合结果见表 3 , 由拟合数据可知, 滤光片在不 同区域拟合得到的 $n$ 值均小于 1 , 说明试样表面生成 的腐蚀层具有一定的阻挡作用。

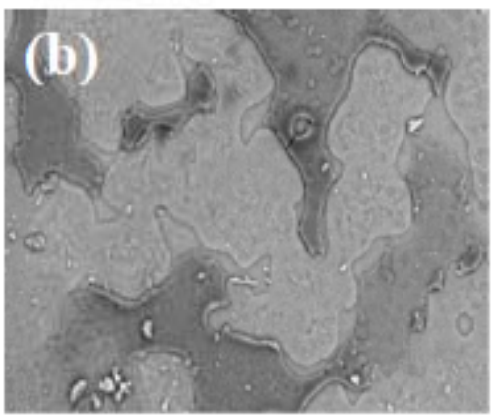

万宁站试验 18 个月(b) Eighteen months' experiment in Wanning

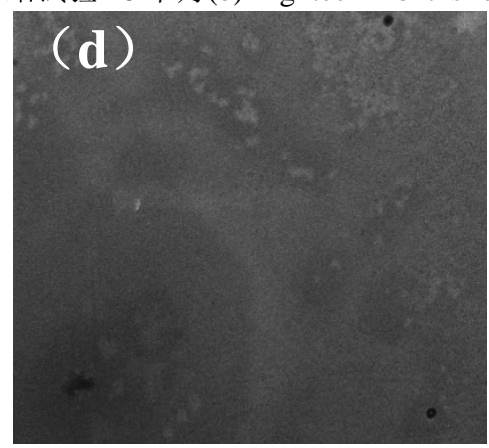

(d) 西双版纳站试验 18 个月

(d) Eighteen months' experiment in Xishuangbanna

Fig.4 The SEM of filters with film

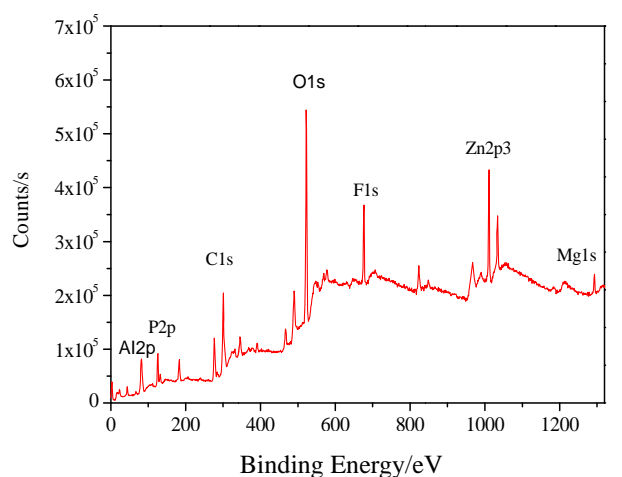

(b) 镀保护膜滤光片(b) The filter with film Fig.5 The XPS of filters precipitated 


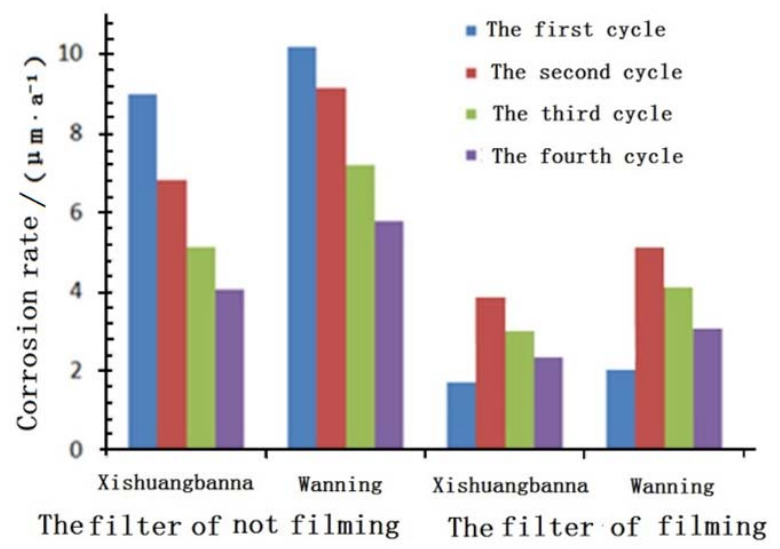

图 6 滤光片在万宁站和西双版纳站的腐蚀速率

Fig.6 The corrosion rate of filter in Wanning and

Xishuangbanna

镀保护膜滤光片不同区域暴露后, 腐蚀失重量百
分比随时间的变化规律如图 8 所示。

从图 8 可以看出, 镀膜滤光片在万宁和西双版纳 的腐蚀失重量百分比与暴露时间遵循 $\mathrm{S}$ 曲线变化规律:

$$
F(t)=\beta /\left(1+\gamma \mathrm{e}^{-c t}\right)
$$

式中: $F(t)$ 为腐蚀失重量百分比; $t$ 为暴露时间; $\beta$ 为 拟合常数; $c$ 为位置参数, 决定了产品退化达到稳定 所需的时间; $\gamma$ 为表征腐蚀速率快慢的常数, 对数据进 行 S 曲线拟合分析, 拟合结果见表 4, 由拟合数据可 知: 滤光片第一个周期腐蚀速率较慢, 说明在不同的 区域, 膜层对滤光片都具有一定的防护作用。第二个 周期滤光片腐蚀速率较快, 腐蚀速率达到最大值, 与 实际检测中出现的滤光片表面膜层腐蚀、龟裂、脱落 等相吻合。第三个周期后腐蚀速率逐渐减小, 说明生 成的腐蚀层对滤光片试样也具有一定的缓蚀作用。

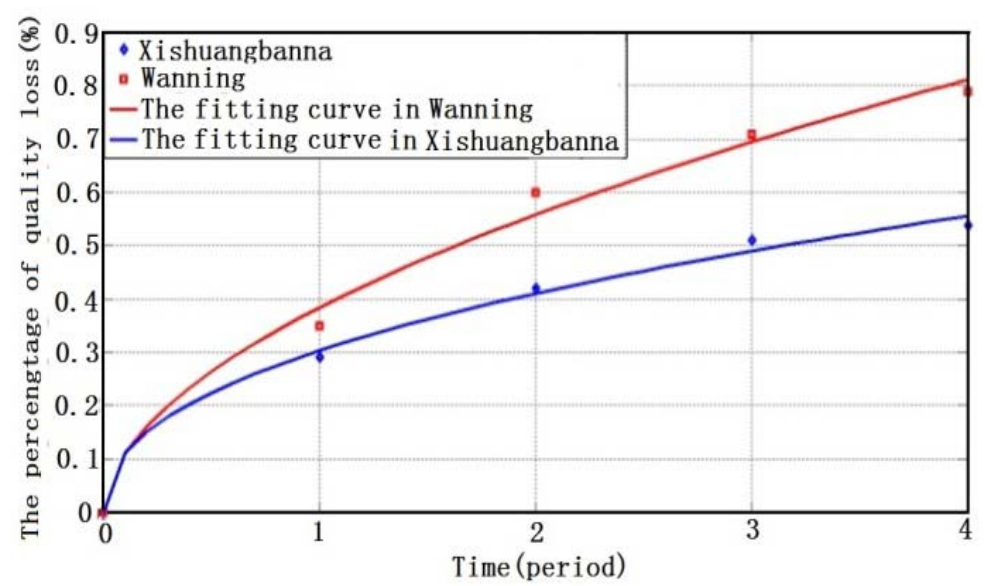

图 7 未镀保护膜滤光片在万宁站和西双版纳站的失重百分比分析

Fig.7 The percentage analysis of quality loss for filter without film in Wanning and Xishuangbanna

表 3 未镀保护膜滤光片在万宁站和西双版纳站暴露的腐蚀失重量分析拟合结果

Table 3 The fitted curve of quality loss for filter without film in Wanning and Xishuangbanna

\begin{tabular}{llccc}
\hline Experiment station & Fitting equation & $A$ & $n$ & $R^{2}$ \\
\hline Wanning & \multirow{2}{*}{$F=A t^{n}$} & 0.384 & 0.5398 & 0.9829 \\
Xishuangbanna & & 0.3225 & 0.3955 & 0.9902 \\
\hline
\end{tabular}

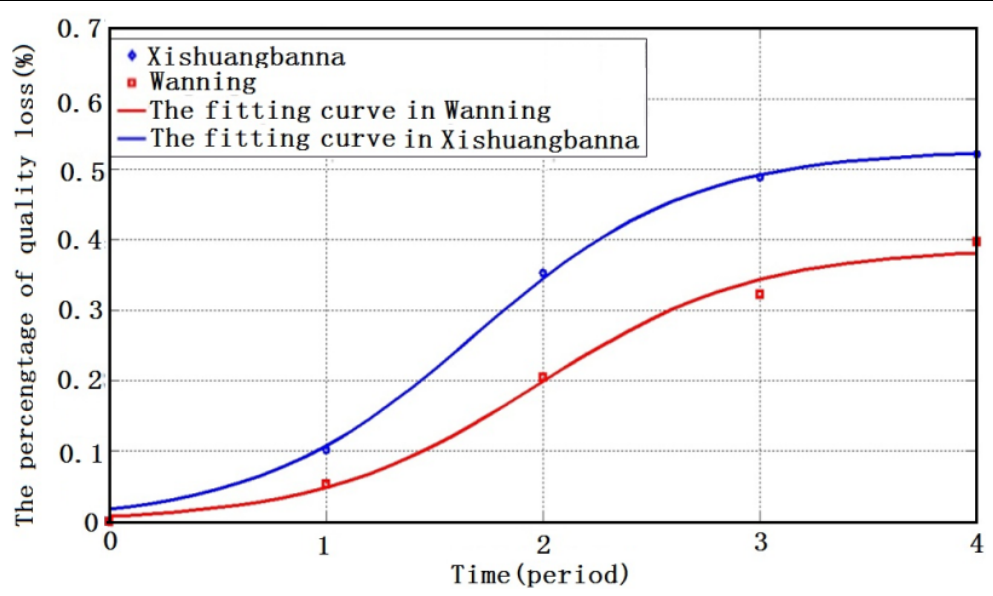

图 8 镀保护膜滤光片在万宁和西双版纳的失重量百分比分析

Fig.8 The percentage analysis of quality loss for filter with film in Wanning and Xishuangbanna 
表 4 镀保护膜滤光片在不同环境下暴露的失重分析

Table 4 The quality loss analysis of filter in different environments

\begin{tabular}{lccccc}
\hline Environment & Fitting function & $\beta$ & $\gamma$ & $c$ & $R^{2}$ \\
\hline Tropical marine climate & $F(t)=\beta /\left(1+\gamma \mathrm{e}^{-c t}\right)$ & 0.4014 & 27.3018 & 2 & 0.9958 \\
Tropical rainforest & & 0.5175 & 28,8922 & 2 & 0.9969 \\
\hline
\end{tabular}

\section{3 结果与讨论}

从不同环境下滤光片的腐蚀情况分析，尽管滤 光片表面镀制保护膜, 但在大气环境中暴露 2 个周 期后, 热带雨林环境和热带海洋环境中暴露的镀保 护膜滤光片表面均出现不同程度的化学元素析出和 膜层脱落现象。暴露 3 个周期后, 滤光片表面防护 层基本失效, 表明保护层在热带雨林和热带海洋环 境下对滤光片的保护作用有限。究其原因, 在湿度 $80 \%$ 以上的热带雨林和热带海洋环境中, 镀保护膜 滤光片的表面极易形成薄的液膜，同时大气中的腐 蚀介质极易沉积在滤光片表面, 由于薄膜表面存在 微孔或裂纹, 水分子和溶解氧等腐蚀介质易通过微 孔或裂纹进入薄膜内部, 且随着时间效应和温湿度 效应的延长，腐蚀介质会和滤光片基底材料发生反 应, 导致滤光片基底产生腐蚀, 随着腐蚀产物持续 增加、堆积、导致膜层起皮、开裂直至脱落。

\section{4 结论}

1)滤光片在热带雨林和热带海洋环境暴露腐蚀 规律基本一致, 前两个周期腐蚀速率较高, 后期逐 渐趋缓。

2)镀保护膜滤光片在热带雨林和热带海洋环境 中的腐蚀速率比未镀膜滤光片的腐蚀速率慢, 说明 镀膜对滤光片腐蚀起到保护作用。

3）滤光片在万宁站的腐蚀速率大于在西双版 纳站的, 说明盐雾及酸性大气环境会加剧滤光片的 腐蚀。

4）镀保护膜滤光片在试验第一个周期时, 腐蚀 速率较小, 后三个周期腐蚀速率变大, 说明保护膜 层对滤光片的有效保护作用较短, 大约为半年。

5)在热带海洋及热带雨林大气环境中长期使用 的光电观瞄装备, 不建议使用磷酸盐玻璃作为滤光 片材料。

\section{参考文献:}

[1] 字正华, 王乔方, 刘剑, 等. LB6 滤光片在亚热带海洋性气候环境中的 腐蚀特性研究[J]. 红外技术, 2015, 37(11): 943-948

ZI Zhenghua, WANG Qiaohang, LI Jian, et al. Corrosion properties of LB6 filter in tropical oceanic climate environment[J]. Infrared
Technology, 2015, 37(11): 943-948.

[2] 陈潇. 透明 LCD 显示技术研究[J]. 光电子技术, 2019, 39(2): 137142. CHEN Xiao. Research of transparent LCD technology[J]. Optoelectronic Technology, 2019, 39(2): 137142.

[3] 徐美君, 杜念娟. 磷酸盐玻璃国内外发展概况 [J]. 建材世界, 2009, 30(3): 53-57.

XU Meijun, DU Nianjuan. Phosphate glass development at home and abroad[J]. The World of Building Materials, 2009, 30(3): 53-57.

[4] 宣卫芳, 胥泽奇, 肖敏, 等. 装备与自然环境试验 $[\mathrm{M}]$. 北京: 航空工 业出版社, 2011: 14-26.

XUAN Weifang, XU Zeqi, XIAO Min, et al. Equipment And Nation Test[M]. Beijing: Aviation Industry Press, 2011: 14-26.

[5] 王乔方, 字正华, 李汝劼, 等. 红外 $\mathrm{Ge}$ 窗口在热带雨林环境中的腐蚀 特性研究[J]. 红外技术, 2014, 36(12): 964-966.

WANG Qiaofang, ZI Zhenghua, LI Rujie, et al. Corrosion properties of Germanium IR window in tropical rainforest environment[J]. Infrared Technology, 2014, 36(12): 964-966.

[6] 刘若冰, 陈勤. 红外焦平面探测器咜存寿命试验研究[J]. 红外技术, 2019, 41(12): 1124-1132

LIU Ruobing, CHEN Qin. Research on storage lifetime test of infrared focal plane array detectors[J]. Infrared Technology, 2019, 41(12): 1124-1132.

[7] 谈婷, 裴景洋, 赵学敏, 等. 红外微型多谱段集成滤光片产品质量考 核方法[J]. 激光与红外, 2020, 50(6): 691-696.

TAN Ting, PEI Jingyang, ZHAO Xuemin, et al. The quality assessment method for infrared micro-multi-band filter[J]. Laser \& Infrared, 2020, 50(6): 691-696.

[8] 王松林, 米高园, 张建付, 等. 中波红外双通道带通滤光片的研制 [J]. 激光与红外, 2017, 47(6): 740-744.

WANG Songlin, MI Gaoyuan, ZHANG Jianfu, et al. Study and preparation of mid-infrared dual channel band-pass filter[J]. Laser \& Infrared, 2017, 47(6): 740-744.

[9] 赵会聪. 带通滤光片的镀制及抗辐照性能研究[D]. 哈尔滨: 哈尔滨工 业大学, 2014.

ZHAO Huicong. Evaporation and Research on Anti-radiation of Bandpass Filter[D]. Harbin: Harbin Institute of Technology, 2014.

[10] 王冲文, 赵宏坤, 刘剑, 等. OLED 显示器热带雨林环境适应性研究 [J]. 红外技术, 2020, 42(6): 542-546.

WANG Chongwen, ZHAO Hongkun, LIU Jian, et al. Dissecting the adaptability of OLED displays in tropical rainforest[J]. Infrared Technology, 2020, 42(6): 542-546. 